\title{
An integrated model to examine the effects of Sustainable Diversion Limits: A case study in the Lower Campaspe catchment
}

\author{
$\underline{\text { S. El Sawah }}^{\text {a,b }}$, R.A. Kelly (nee Letcher) ${ }^{\mathrm{c}}$, C. Beverly ${ }^{\mathrm{d}}$, K. Stott ${ }^{\mathrm{d}}$, M.J. Patrick ${ }^{\mathrm{a}, \mathrm{b}}$ J. Kath $^{\mathrm{e}}$, \\ B.F.W. Croke ${ }^{\mathrm{a}, \mathrm{b}}$, M.E. Qureshi ${ }^{\mathrm{f}, \mathrm{g}}$, B. Courtney-Barrer ${ }^{\mathrm{a}}$, M.J. Asher ${ }^{\mathrm{a}}$, A. Roberts ${ }^{\mathrm{h}}$ and A.J. Jakeman ${ }^{\mathrm{a}, \mathrm{b}}$ \\ ${ }^{a}$ Integrated Catchment Assessment and Management Centre, The Fenner School for Environment and \\ Society, Australian National University, Canberra, ACT, 0200 Australia \\ ${ }^{b}$ National Centre for Groundwater Research and Training, (NCGRT) \\ ${ }^{c}$ isNRM Pty Ltd, PO Box 8017, Trevallyn, Tasmania, Australia \\ ${ }^{d}$ Victorian Department of Environment and Primary Industries \\ ${ }^{e}$ Institute for Applied Ecology and MDB futures CRN, University of Canberra, ACT 2601 Australia \\ ${ }^{f}$ CSIRO, Water for a Healthy Country National Research Flagship.Canberra \\ ${ }^{g}$ The Fenner School for Environment and Society, Australian National University, Canberra, ACT, 0200 \\ Australia \\ ${ }^{h}$ Natural Decisions Pty Ltd, Wangaratta Australia.
}

Email: sondoss.elsawah@anu.edu.au

\begin{abstract}
Setting limits for consumptive water extraction from the Murray-Darling Basin, known as Sustainable Diversion Limits (SDLs), is a key feature of recent water reforms. The ecological and socioeconomic impacts of SDLs have been assessed for the entire Murray-Darling Basin. However, there is still little understanding of how these limits will play out at the catchment scale and at more localised levels. To build this understanding, the SDLs (estimates and rules) need to be examined using a multidisciplinary framework that includes water management policies, climate change projections, the nature of surface watergroundwater systems, and water-dependent economic and ecological systems. This paper presents an ongoing collaborative project between the research team in the National Centre for Groundwater Research and Training (NCGRT), Victorian Department of Environment and Primary Industries, North Central Catchment Management Authority and Goulburn-Murray Water. It examines the effects of implementing the SDLs for the Lower Campaspe catchment in Victoria in terms of tradeoffs between the profitability of agricultural production and ecosystem response, especially groundwater dependent ecosystems. The model under development is also intended to be flexible enough to investigate adaptation options for landholders and water policy initiatives. In undertaking such an integrated assessment project, the research team brings together researchers from multiple disciplines, including hydrology, hydrogeology, ecology, resource economics, social science and systems science. The project has applied an integrated modelling approach which focuses on working closely with project stakeholders to identify modelling questions, share results and seek feedback. Our aim is to develop an integrated modelling framework that can be reapplied in other catchments to address stakeholders' questions and concerns with regard to the implementation of the SDLs at the local level. In this paper, we give a brief overview of the design of the integrated model under development, and its key components and interactions.
\end{abstract}

Keywords: Integrated assessment, integrated modelling, tradeoffs, Sustainable Diversion Limits, Campaspe 
Sawah et al., An Integrated Model to Examine the Effects of Sustainable Diversion Limits: A Case Study in the Lower Campaspe Catchment

\section{INTRODUCTION}

The Lower Campaspe River catchment in the Murray-Darling Basin (MDB) extends from Lake Eppalock in the south, flowing north to meet the Murray River at Echuca. The area contains the towns of Rochester and Elmore. It covers an area of approximately $2,100 \mathrm{~km}^{2}$. The Campaspe system is heavily regulated to supply water for irrigation, stock and domestic, and urban water demand.

The hydrological regime of the Campaspe River was changed significantly by the construction of Lake Eppalock (312GL storage capacity), and irrigation releases have significantly affected flow regimes (quality and quantity). Severe prolonged drought, combined with substantial irrigation releases, has degraded the river health, and dependent ecosystems. The Murray-Darling Basin Commission Sustainable Rivers Audit (SRA) 2008 rated the overall health of the Campaspe catchment as "very poor".

The key groundwater aquifers in the Lower Campaspe Valley Water Supply Protection Area (WSPA) are the Shepparton Formation sands and the underlying Deep Lead coarse sands and gravels. The Deep Lead aquifer is known for its high yields and good quality. However, in the Upper Shepparton Formation, groundwater salinity is high and is a threat to the Campaspe Deep Lead aquifer. Even low rates of recharge from the Upper Shepparton Formation could cause long-term increases in groundwater salinity in the Deep Lead aquifer. Groundwater use increases in dry periods, with decreases in surface water availability. Groundwater dependent ecosystems are thought to be limited to river red gum populations along the river corridor. Decreased river flows from drought, increased irrigation or declines in groundwater levels could impact Groundwater Dependent Ecosystems (GDEs) by decreasing water availability.

In recent years, there have been significant changes in water resource management in the Campaspe system caused by several drivers, including water reform in the MDB, prolonged drought, shifts in land use, and Government water efficiency and buyback programs. One of the key challenges ahead is the introduction of the Sustainable Diversion Limits (SDL) to surface and groundwater. The SDL proposal for the Campaspe region equates to reductions in the current long-term average surface water diversion limit from $155 \mathrm{GL} / \mathrm{y}$ to between 115 GL and 103 GL per year (reduction between 40 - 52 GL per year or $26 \%$ to $33 \%$ ). The SDL implementation will significantly change the regional economic landscape and agricultural enterprise profitability. Given that SDLs are estimated using broad-scale, basin-wide data and global modelling approaches, these estimates could vary substantially from local, site specific assessments. The reported estimates of the sustainable diversion limits do not account for climate change projections, current irrigation practices, and economic impacts at a finer scale. Nor do they investigate adaptation options and new water policy initiatives such as opportunities for conjunctive water use and flexible irrigation carryover rules. These issues are being addressed through the creation of an integrated model. This paper describes the constructs of this modelling framework under development using the Lower Campaspe catchment as an exemplar.

\section{OBJECTIVES AND APPROACH}

The integrated model is being developed as part of a participatory research effort. It builds on integrated assessment processes (e.g. Jakeman and Letcher, 2003) and modelling experiences in the Namoi catchment (e.g. Letcher et al., 2004). Key stakeholders have been engaged to help identify modelling questions and to provide expert local knowledge, models and data which are being used to inform the integrated model. Scenario runs will be designed in consultation with these key stakeholders, results shared and their feedback on potential impacts sought. Engagement will also focus on identifying a custodian for the model and exploring the potential for its further application. Key stakeholder engagement is being undertaken by social scientists to ensure the model and its results are relevant and that there is confidence in its outputs and recommendations. To date three major engagement activities have been undertaken with the main stakeholders:

1. A stakeholder scoping workshop to identify management questions and the scope of the project

2. Delivery of a scoping review incorporating outcomes from the workshop with understanding gained through a literature and data review

3. A stakeholder workshop to identify modelling zones based on local knowledge of groundwatersurface water interactions, the agricultural production system and planned structural changes to irrigation water supply.

During the scoping workshop, stakeholders indicated several priority questions to be addressed:

1. How reasonable are the SDL numbers defined by the Murray-Darling Basin Authority (MDBA)? What is the connection between SDLs and the benefits and outcomes of reduced water use? Could SDLs be set at a lower level and still achieve the same outcome? 
Sawah et al., An Integrated Model to Examine the Effects of Sustainable Diversion Limits: A Case Study in the Lower Campaspe Catchment

2. How can the large volumes of environmental water be best used (timing and location) in order to balance water irrigation and ecological outcomes, to gain the most efficient use of environmental water? This should consider:

a. Year-to-year planning

b. Multi-year planning to manage risks

c. Cases of conflict over river delivery capacity

d. Long term projections in the context of climate change

e. Potential for carryover water use and rules on when to use it and when to hold it aside for a later period.

3. What rules could/should the Commonwealth Environmental Water Holder use to best manage its water releases? What are the potential impacts on farming enterprises?

4. What are the impacts of Government purchase and trading of water entitlements on water markets, irrigation, and subsequent socio-economic impacts (under different water availability scenarios and especially during drought time)?

5. What are the likely nature and magnitude of impacts from reduced water supplies on agricultural production, enterprise profitability and the broader community?

6. What role is there for government to assist communities in adjusting to changes, in particular in keeping farmers productive?

In addition, two further questions were identified in the literature review:

1. How will the Commonwealth groundwater buyback program operate? What are the impacts of different management schemes on groundwater price?

2. What are the impacts of intercepted water from the upper catchments on water allocation and water available for agriculture?

It is intended that the integrated assessment process and associated model developed in this project will be capable of contributing information to assist in answering all of these questions. The focus of scenario analysis undertaken during the life of the project will be refined in conjunction with key stakeholders once the model development is complete. It is expected that scenarios and model outputs relating to these key questions will be the focus of analysis.

\section{MODELLING FRAMEWORK}

The integrated model being developed to answer these questions incorporates components from a broad range of disciplines: surface and groundwater hydrology; economic modelling of agricultural production decisions; and the ecological impacts of changes in surface and groundwater available to natural systems through changes in irrigation water supply and potential alternative environmental release rules. The basic conceptual model that is being used for integrating these components is shown in Figure 1 below.

This integrated model framework is applied over a nodal network based on modelling regions identified with our key stakeholders. These regions between nodes are zones in the Lower Campaspe based on irrigation schemes and agricultural land uses. Links among nodes are represented in Figure 1 by the small arrows, transferring surface water and in some cases groundwater flows from upstream to downstream nodes. A map of the modelling zone underlying the nodal network is shown in Figure 2. The geographic boundaries and land use characteristics of these zones are given in Table 1. 
Sawah et al., An Integrated Model to Examine the Effects of Sustainable Diversion Limits: A Case Study in the Lower Campaspe Catchment

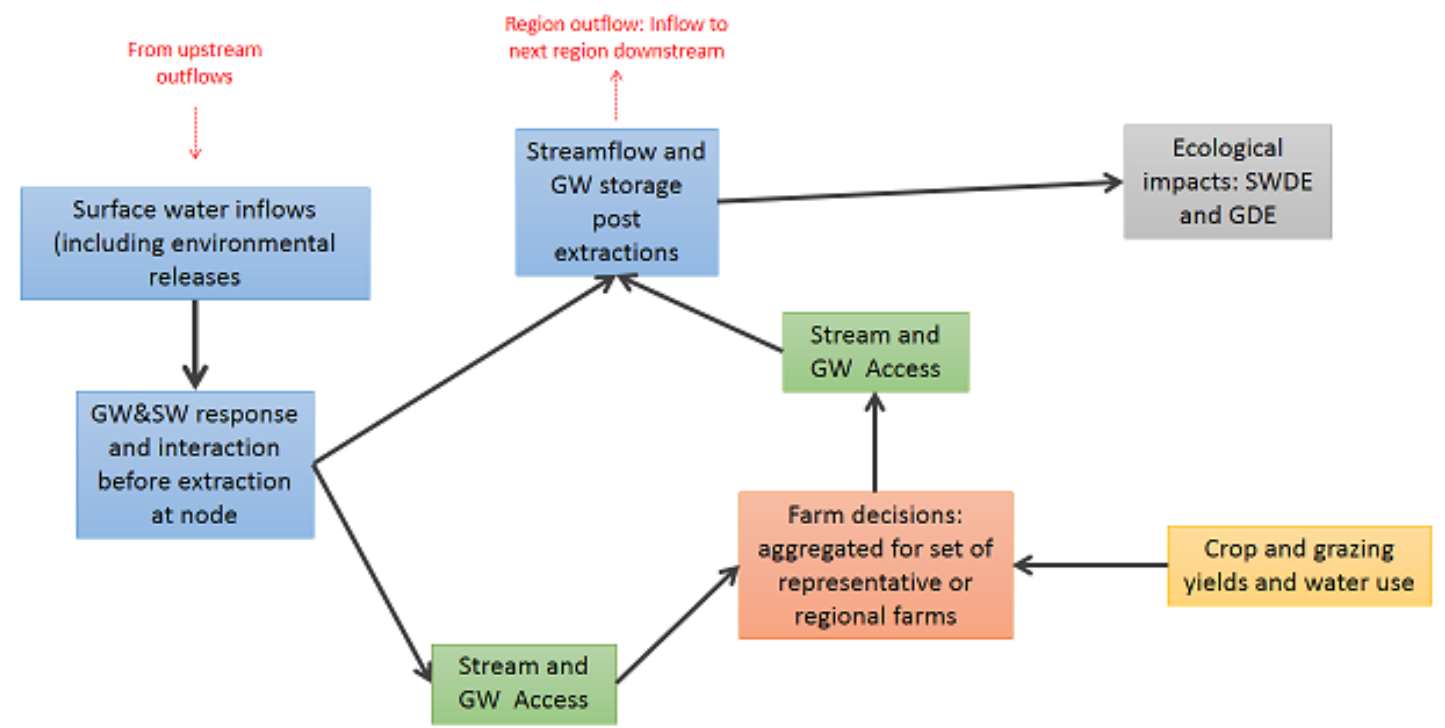

Figure 1: Basic conceptual model framework underlying the integrated model (for a given region between two nodes)

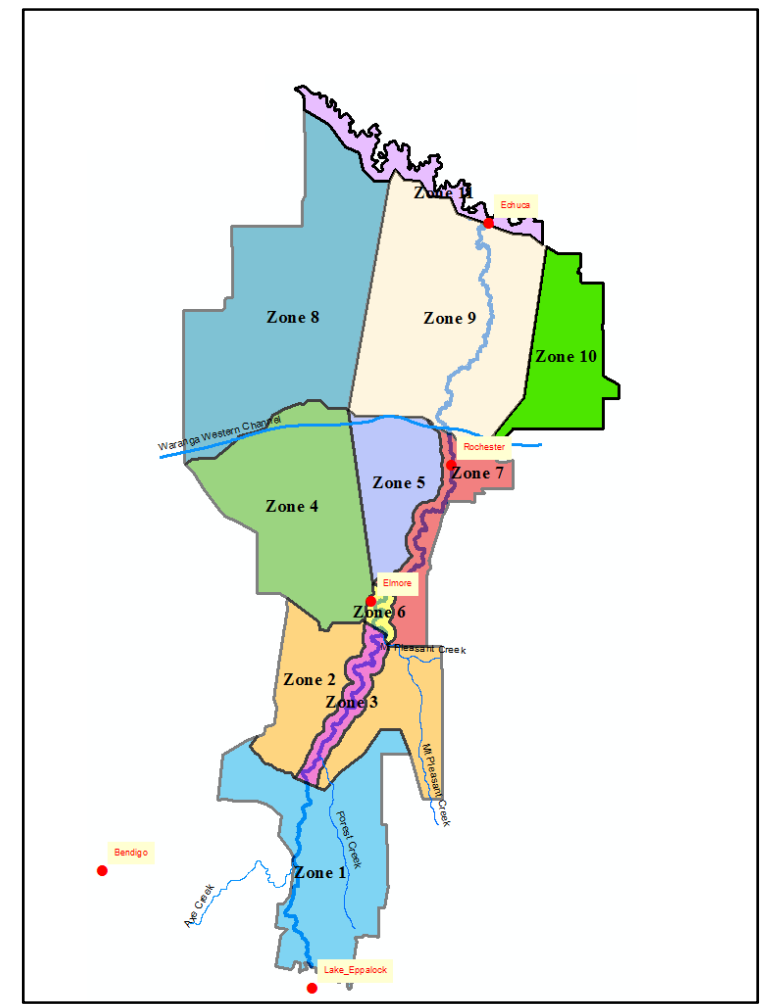

Figure 2: Modelling zone map for the Lower Campaspe River catchment 
Sawah et al., An Integrated Model to Examine the Effects of Sustainable Diversion Limits: A Case Study in the Lower Campaspe Catchment

Table 1: Modelling zone characteristics

\begin{tabular}{|c|c|c|}
\hline Zone & Boundary description & Major production systems (area in ha) \\
\hline 1 & $\begin{array}{l}\text { Extends from Lake Eppalock to south of } \\
\text { Barnadown weir }(406201) \text {, just before Campaspe } \\
\text { merge with forest creek. Forest creek primarily runs } \\
\text { through zone } 1 .\end{array}$ & $\begin{array}{l}\text { Mixed farming and grazing (14,918 ha); Orchards (58ha); } \\
\text { Vineyard (140 ha) }\end{array}$ \\
\hline 2 & $\begin{array}{l}\text { East and West of Campaspe River from just south } \\
\text { of Barnadown weir to south Elmore. Mt Pleasant } \\
\text { creek passes through the East side of the zone and } \\
\text { Zone } 3 \text { extends through zone 2's centre. }\end{array}$ & Mixed farming and grazing $(15,057 \mathrm{ha}) ;$ Vineyard (370 ha) \\
\hline 3 & $\begin{array}{l}\text { Along Campaspe River just south of Barnadown } \\
\text { weir to south Elmore at Mt Pleasant's merge with } \\
\text { the Campaspe River. }\end{array}$ & $\begin{array}{l}\text { Mixed farming and grazing (1,913 ha); Livestock Production } \\
\text { mostly Sheep ( } 38 \mathrm{ha})\end{array}$ \\
\hline 4 & $\begin{array}{l}\text { Begins West of Mt Pleasant's merge with the } \\
\text { Campaspe River south of Elmore and extends to } \\
\text { WWC West of Rochester. Within Western } \\
\text { Campaspe-Rochester irrigation zones. }\end{array}$ & $\begin{array}{l}\text { Mixed farming and grazing (22,862 ha); General Cropping } \\
(219 \text { ha) }\end{array}$ \\
\hline 5 & $\begin{array}{l}\text { Begins just north of Elmore and extends to WWC } \\
\text { West of Rochester. It is also within Campaspe - } \\
\text { Rochester irrigation zones. }\end{array}$ & $\begin{array}{l}\text { Mixed farming and grazing (5,639 ha); Livestock Production } \\
\text { mostly Dairy Cattle }(2,169 \mathrm{ha})\end{array}$ \\
\hline 6 & $\begin{array}{l}\text { Follows Campaspe River (slightly east and west of } \\
\text { River) near Elmore, begins at Mt Pleasant's merge } \\
\text { with the Campaspe River south of Elmore and ends } \\
\text { just north of Elmore. }\end{array}$ & $\begin{array}{l}\text { Mixed farming and grazing ( } 334 \text { ha); Livestock Production } \\
\text { mostly Dairy Cattle (63 ha) }\end{array}$ \\
\hline 7 & $\begin{array}{l}\text { East boundary contains and follows the Campaspe } \\
\text { River from just north of Elmore to its convergence } \\
\text { with the WWC north of Rochester. It falls within } \\
\text { east Campaspe-Rochester irrigation zone }\end{array}$ & $\begin{array}{l}\text { Mixed farming and grazing }(3,541 \text { ha }) ; \text { Livestock } \\
\text { Production mostly Dairy Cattle }(634 \text { ha); General Cropping } \\
(53 \text { ha); Livestock Production mostly Beef Cattle }(43 \text { ha })\end{array}$ \\
\hline 8 & $\begin{array}{l}\text { Begins just north of WWC, west of Rochester (part } \\
\text { of WWC runs through south most border of zone), } \\
\text { extends north to zone } 11 \text { near Murray. It lies within } \\
\text { west Campaspe-Rochester Irrigation district. }\end{array}$ & $\begin{array}{l}\text { Mixed farming and grazing }(20,891 \text { ha); Livestock } \\
\text { Production mostly Dairy Cattle }(12,083 \text { ha); General } \\
\text { Cropping (1,588 ha); Livestock Production mostly Beef } \\
\text { Cattle ( } 303 \text { ha); Domestic Livestock Grazing (152 ha); } \\
\text { Livestock Production mostly Sheep ( } 93 \text { ha); Vineyard ( } 83 \\
\text { ha) }\end{array}$ \\
\hline 9 & $\begin{array}{l}\text { Just north WWC and Rochester, contains } \\
\text { Campaspe River and Campaspe drains, extends } \\
\text { north to Echuca (border of zone 11) where } \\
\text { Campaspe converges with Murray. Within both } \\
\text { East and west Campaspe-Rochester Irrigation } \\
\text { districts. }\end{array}$ & $\begin{array}{l}\text { Mixed farming and grazing }(19,892 \text { ha); Livestock } \\
\text { Production mostly Dairy Cattle }(8,669 \text { ha); General } \\
\text { Cropping ( } 613 \text { ha); Livestock Production mostly Beef Cattle } \\
\text { ( } 273 \text { ha); Livestock Production mostly Sheep ( } 88 \text { ha); } \\
\text { Market Garden mostly vegetables (93ha) }\end{array}$ \\
\hline 10 & $\begin{array}{l}\text { Begins just North of WWC on east side of } \\
\text { Rochester, within east Campaspe-Rochester } \\
\text { Irrigation district. }\end{array}$ & $\begin{array}{l}\text { Mixed farming and grazing ( } 6,778 \text { ha); Livestock Production } \\
\text { mostly Dairy Cattle (4,339 ha); Livestock Production mostly } \\
\text { Beef Cattle ( } 157 \text { ha) }\end{array}$ \\
\hline 11 & Follows Murray river, far north zone. & $\begin{array}{l}\text { Mixed farming and grazing (1,063 ha); Livestock Production } \\
\text { mostly Dairy Cattle (421 ha); Vineyard ( } 60 \mathrm{ha})\end{array}$ \\
\hline
\end{tabular}

\section{MODELLING COMPONENTS}

\subsection{Surface water modelling}

A model of the Lower Campaspe catchment (downstream of Lake Eppalock), has been developed using a combination of the IHACRES rainfall runoff model (Croke and Jakeman, 2004; Andrews et al., 2013), and a lag-route routing model (Croke et al., 2006). The aim of this model is to produce streamflow at specific sites (or nodes) in the lower Campaspe catchment (with some of the nodes ungauged) representing the outlet of residual subcatchments. The IHACRES model is applied to the local catchment area (excluding areas draining to upstream nodes) for each node. As such, parameter values for each node are estimated using a similarity method. The modelled flows at the upstream sites are routed down to the current node, and the 
Sawah et al., An Integrated Model to Examine the Effects of Sustainable Diversion Limits: A Case Study in the Lower Campaspe Catchment

local contribution added to estimate the total natural flow at the current node. Extractions from surface and groundwater are then used to estimate the total flow as well as the groundwater storage.

The routing of flows between each node is carried out using a lag-route approach. This approach uses a combination of a delay to capture the time taken for a peak to propagate down a reach, and an exponentially decaying store to capture the dispersion of the peak (Croke et al. 2006). Given the model is running at a daily timestep, a fractional delay is considered, with a fraction of the input reaching the downstream node on the same day, and the remainder on the following day. This means that the propagated flow is given by:

$$
Q_{u d, k}=-\alpha_{u d} Q_{u d, k}+\left(1+\alpha_{u d}\right)\left[\gamma_{u d} Q_{u d, k}+\left(1-\gamma_{u d}\right) Q_{u d, k-1}\right]
$$

\subsection{Surface water-groundwater modelling}

A spatially (previously developed) distributed multi-layered finite difference groundwater model of the Lower Campaspe catchment was updated and recalibrated. The modelled layers represented the Shepparton Formation (upper and lower), Newer Volcanics, Calivil Formation and Palaeozoic basement aquifers. A metamodel of this model is being developed that is integrated with the surface water model described in the previous section. It is also a spatio-temporal model but lumped spatially to polygons representing the residual subcatchments between the nodes. The metamodel employs a conceptualisation of the key hydrological processes (as in Blakers et al. 2011) and includes two groundwater layers: a shallow system that contributes baseflow to the river, and a deeper groundwater system that is used as a water resource. The model therefore consists of three components: the rainfall-streamflow model representing runoff and baseflow from the shallow aquifer system for each subcatchment; a groundwater mass balance model for the deeper aquifer system, and a lag-route routing model capturing the flux of water between nodes.

The rationale for a metamodelling approach is to facilitate its incorporation into the fully integrated hydrological-economic-ecological model. Not only will a metamodel have a faster runtime than a fully distributed finite difference model and be easier to incorporate in the integrated model but it will enable uncertainty analysis and developed to be as accurate at predicting subcatchment-scale flows and groundwater-surface water interactions. Pseudo Monte Carlo simulations of the fully distributed groundwater model produce data to which the conceptual, subcatchment scale metamodel is fit with the desired degree of accuracy.

\subsection{Ecological modelling}

This component aims to determine the spatial relationship between groundwater depth and quality (e.g. salinity) and river red gum canopy condition along the Campaspe River. The nature of the relationship between groundwater level and canopy condition will enable insights to be developed in relation to the concepts of resistance and resilience and how this could potentially impact on environmental water allocation planning.

Resistance is defined here as the amount of deviance from some prior condition after some defined disturbance has occurred. In the context of this study, a red gum individual or population, which shows lower mortality and less change in condition (e.g. canopy cover) after a disturbance, such as drought, is more resistant than an individual or group that shows greater mortality or greater declines in condition (West and Salam, 2003). Resilience refers to the ability of that individual or population to recover or return to some predefined state after a disturbance, such as drought. In relation to river red gums, this may refer to the ability of the population to recover through recruitment or regrowth of canopy (after West and Salam, 2003).

As part of this study, we will relate groundwater depth and quality with LiDAR data, which gives an indication of canopy condition (fractional count cover), across the riparian areas of the Campaspe catchment. The LiDAR data provides a spatially detailed snapshot of tree condition, during dry conditions in 2009/2010 when groundwater relationships should be of the most importance to riparian vegetation. This modelling will provide us with information about whether groundwater moderates the effects of dry conditions on vegetation and also which sections of riparian vegetation were most resistant to the 2009/2010 dry conditions. Using this information we will then compare sections of riparian vegetation with poor and good groundwater conditions through time using Modis Enhanced Vegetation Index time-series data. We will compare the response of vegetation to precipitation and surface flow conditions in areas with different groundwater conditions. This will provide indications of whether the resilience (i.e. the recovery ability) of riparian vegetation to changes in climate (i.e. precipitation) varies in relation to groundwater conditions.

There is an underlying assumption that environmental watering is always ecologically beneficial for the targeted asset or site, however, this might not always be the case. The identification of resistant and/or 
Sawah et al., An Integrated Model to Examine the Effects of Sustainable Diversion Limits: A Case Study in the Lower Campaspe Catchment

resilient red gum populations could potentially help managers design strategies that would optimise how to manage environmental water and to ensure successful long term outcomes for river red gum populations in the Lower Campaspe catchment.

\subsection{Economic modelling}

This component aims to generate the decisions that farmers make in regard to their land and water use (e.g. farming activities, and demand from available water sources) under different economic and water availability conditions. It is essential to integrate the hydrological and hydrogeological boundaries of the study area with the farm-scale analysis. Therefore, modelling zones (identified in Figure 2) are treated as one farm that represents the production systems dominant in these regions. Production systems are characterised according to several factors, including their structural attributes (e.g. farm size, farming activities), and landscape properties (e.g. water access, salinity levels). The typology of representative farms draws on different water use and land use data sources, such as the Victorian Land Use Information System (VLUIS).

The analytical framework used in this component builds on the mathematical modelling approach developed by Qureshi et al., (2012), with some additional features, such as groundwater access and the option of carrying-over unused water licenses to the following irrigation seasons. In the model, farmers attempt to maximise their seasonal profits given a set of policy, land, and water constraints. Depending on their types, farms may have access to surface and/or groundwater sources in addition to direct rainfall. At the beginning of each season, farmers decide on the portfolio of farming activities (e.g. grain, fruit, dairy, and beef) that optimises their farm's profit. The model is coded in the General Algebraic Modelling System (GAMS). Results from the model will give insight into the economic viability of different farming activities, and therefore, the structural adjustment that the irrigation industry needs to make to better respond to future changes.

\section{CONCLUSION AND NEXT STEPS}

This paper presents an early glimpse of the integrated modelling framework under development for the Lower Campaspe area. The model will be used to examine the economic and ecological impacts of different future water availability scenarios. A workshop will be run to share model results and recommendations with relevant stakeholder to facilitate a dialogue about necessary steps required for effective implementation of the SDLs due by 2019.

\section{REFERENCES}

Andrews, F., Croke, B.F.W. and Jakeman, A.J. (2011) An open software environment for hydrological model assessment and development. Environmental Modelling and Software, 26: 1171-1185.

Blakers, R.S., Croke, B.F.W. and Jakeman, A.J. (2011). The influence of model simplicity on uncertainty in the context of surface - groundwater modelling and integrated assessment. In Chan, F., Marinova, D. and Anderssen, R.S. (eds) MODSIM2011, 19th International Congress on Modelling and Simulation. Modelling and Simulation Society of Australia and New Zealand, December 2011, pp. 3833-3839.

Croke, B.F.W., R.A. Letcher and A.J. Jakeman, (2006). "Development of a flow network for the Namoi River Basin, Australia", Journal of Hydrology, 319:, 51-71. doi:10.1016/j.jhydrol.2005.07.001.

Croke, B.F.W. and A.J. Jakeman, (2004). A Catchment Moisture Deficit module for the IHACRES rainfallrunoff model. Environmental Modelling and Software. 19:1-5 (plus Corrigendum to "A Catchment Moisture Deficit module for the IHACRES rainfall-runoff model” [Environ. Model. Softw. 19 (1) (2004) 1-5], 20 (2005), 977).

Jakeman, A.J. and Letcher, R.A. (2003). Integrated Assessment and Modelling: Features, Principles and Examples for Catchment Management. Environmental Modelling and Software, 18: 491-501.

Letcher, R.A. Jakeman, A.J. and Croke, B.F.W. (2004). Model development for integrated assessment of water allocation options. Water Resources Research, 40: W0552.

Qureshi, M.E., Mainuddin, M., Marvanek, M., Elmahdi, A., Connor, J. and Whitten, S. (2012). 'Irrigation Futures for the Murray Basin - Technical Documentation, Canberra', CSIRO: Water for a Healthy Country National Research Flagship.

West, J. M. and Salam, R. V. (2003). Resistance and Resilience to Coral Bleaching: Implications for Coral Reef Conservation and Management. Conservation Biology, 17: 956-967. 